\title{
Teaching materiality and religion: experience and products
}

Dominic Corrywright and Tom Cosgrove (Oxford Brookes University, UK)

\section{Introduction}

The structure of modernity is generated by the fictive (utopian, placeless) status of formulations of meaning. The ultimate meanings of people's lives are determined by others - books, institutions, intellectuals - or on the whole modalities removed from an immediate living reality and context (Philip Arnold 2005: 10,048). A core challenge for the academic teaching of religion and theology is for students to understand the experience and the "living reality" of religions. A common solution adopted by tutors is to design fieldwork and study visits whereby students may engage with the material culture and context of religious practice. This short paper outlines one such approach, a study trip to southern India organized for Oxford Brookes University students. There are a number of related pedagogical objectives which inform, and are informed by, the actual process and practice of undertaking this study visit. These include: a "products-based" approach to learning whereby students produce an assignment that is multivalent (as assessment for study, and public showcase of undergraduate work), a focus on undergraduates as researchers, and the development of "inheritance mechanisms" (Chang and Jackson 2007) as a resource for future learning. Such study trips are often valuable tools that enable pedagogical and personal transformation (see Figures 1-3).

\section{Project: The Yatra Project}

The Hindi term yatra, translated as pilgrimage and journey, includes notions of material journey, conceptual and cognitive journeys and imagined journey. Yatra can be the movement between places and between positions of understanding. Yatra as pilgrimage in traditional Hinduism is often a journey to a confluence of sacred rivers, and for the pilgrim, or yatri, is psychologically and spiritually a journey of transition or of transformation ... One might also say that yatra is at the core of learning and teaching. In Higher Education we emphasise the internal cognitive yatra, but the experience for the learners is often more embodied (Corrywright and Cosgrove 2012).

The initial objective for the Yatra Project at Oxford Brookes University was to create a series of webbased multi-media learning objects, in collaboration with Jyoti Sahi and Sangam Ashram, utilizing Sahi's publications, blogs and artwork to explore these themes. For a number of years we have been working with Jyoti Sahi, a theologian and painter based in southern India, whose work reflects a number of key themes such as enculturation, marginalization, primalism, Dalits and the dispossessed, and the relation between art and spiritualities. The learning objects feature the images alongside critical commentaries, interviews and discussion of key concerns of the theme. The learning objects were initially trialed on the History, Philosophy and Religion department Virtual Learning Environment (VLE) for use in Special Topics and Research Topics modules at undergraduate levels five and six, before being released (on the Oxford Brookes Research Archive and Digital Asset Repository, RADAR) for wider use. The packages are designed for wider use by students studying on anthropology, culture, communications, philosophy, sociology, art history, geography, and education 
programs. A further objective was to develop and build student research projects on themes emerging from the learning objects and regular study visits to Sangam, in India. Sangam is run by an educational team with considerable experience in facilitating short study visits for academic groups and teachers. We have organized five annual study trips. In the first year this included only students on the Religion and Theology program, but in later years has included students on other programs from the Faculty of Humanities and Social Sciences. Student research projects have been supported on a range of topics and fields including diaspora religion, indigenous religions, education, politics, geography, culture and art.

\section{Products}

[M]ost of my students have little experience thinking about or consciously making material culture. They are also likely to be unfamiliar with the notion that their bodies are intellectual tools, or that the world of seemingly immediate perception is actually the result of processes that include cultural learning and skill development (Carp 2007: 6).

The Yatra Project proposed the development of two interrelated products: (1) the production and delivery of six web-based learning packages, and (2) the development of collaborative partnerships. In collaboration with Sahi and Sangam ashram, we created a series of web-based multi-media learning objects, utilizing his artwork to explore these themes. Students engage in research activity and are required to produce their own electronic products in the form of posters or short video presentations that are presented at the annual University Undergraduate Research Conference. The posters are re-usable and have been included in "Posters in Parliament" showcasing undergraduate research at the Houses of Parliament, and the National Undergraduate Research conference.

Moreover, the posters, and other student work such as articles and reviews, add to the repository of sources, forming an "inheritance mechanism" for future students.

We have continued to focus on the key project aims of (1) developing e-learning objects for use on the VLE and RADAR, and (2) including students from a variety of programs in the study visits.

However, the project has grown with other important products, specifically in undergraduate work presented at undergraduate research conferences. We have also identified two issues related to sustainability and the importance of developing "inheritance mechanisms" (1) to incorporate student work in the resources, and (2) to continue the study visits to India and extend the range of students and staff leading such visits. These extrinsic products provide a recognizable pedagogic set of benefits, but we maintain that active engagement with facets of material culture, such as is afforded by study and field trips, is intrinsically valuable for students in their learning and is also a core aim for teaching.

\section{References}

Arnold, Philip P. 2005. "Materiality". In Vol 15 of the Encyclopedia of religion, 2nd ed, edited by L. Jones. Detroit: Macmillan Reference USA, 10047-10050. Gale Virtual Reference Library.

Chang, H. and C. Jackson. 2007. "An Element of Controversy: The Life of Chlorine in Science, Technology and Medicine" In Vol 13 of the BSHS Monograph Series. London: British Society for the History of Science.

Corrywright, Dominic and Tom Cosgrove. 2012. Enhancing electronic and embodied learning experiences. Brookes E-Journal of Learning and Teaching 4 (1). 
http://bejlt.brookes.ac.uk/shortarticle/enhancing

electronic and embodied learning experiences/.

Carp, Richard M. 2007. "Teaching religion and material culture." Teaching Theology and Religion 10 (1): $2-12$ 